\title{
A ENFERMAGEM COMO OBJETO DA HISTÓRIA: UMA REFLEXÃO SOBRE O TEMA
}

\author{
NURSING AS OBJECT OF HISTORY: A PROPOSAL TO REFLECT ON THE \\ THEME \\ LA ENFERMERIA COMO OBJETO DE LA HISTORIA: PROPONIENDO UNA \\ REFLEXIÓN SOBRE EL TEMA
}

\author{
Regina Maria dos Santos' \\ $M^{a}$ Cristina S. Figueiredo Trezza ${ }^{2}$ \\ Zandra Maria Cardoso Candiotti ${ }^{3}$ \\ Joséte Luzia Leite ${ }^{4}$
}

\begin{abstract}
RESUMO: Neste estudo propomos refletir sobre a Enfermagem como objeto da História. Ancoramos nossa proposta nos estudos que vêm sendo realizados sobre a História da Enfermagem Brasileira e na abertura que a História Nova confere aos estudos históricos. Para tanto, buscamos compreender a História da Enfermagem Brasileira e as circunstâncias sociais que determinaram o desenvolvimento da profissão nessa ou naquela direção. Apresentamos algumas propostas metodológicas comumente utilizadas em estudos históricos, propondo a história oral e a análise de documentos como métodos de coleta de dados. A releitura dos acontecimentos sociais, a partir dos dados coletados, é capaz de favorecer o entendimento da importância dos estudos sobre a História da Enfermagem no reconhecimento da sua identidade profissional, como contribuição para o fortalecimento da categoria. Esperamos estimular a produçăo de novos trabalhos sobre o tema e, principalmente, alertar para a necessidade de preservarmos nossa memória.
\end{abstract}

PALAVRAS-CHAVE: Enfermagem, história da enfermagem, história nova

\section{CONSIDERAÇÕES INICIAIS}

A motivação para escrever este trabalho cresceu ao longo da disciplina "Análise das Fontes de Pesquisa em História da Enfermagem Brasileira", durante o curso de doutorado em Enfermagem, na Escola de Enfermagem Anna Nery - Universidade Federal do Rio de Janeiro, onde estávamos atuando, como alunas e professora.

No programa de doutorado desta Escola, existe uma linha de pesquisa em História da Enfermagem Brasileira (HEB) e na instituição funciona o Núcleo de Pesquisa em História da Enfermagem Brasileira (Nuphebras)onde são semanalmente discutidos estudos sobre o tema e esse exercicio nos permitiu visualizar a importância do conhecimento da HEB como um instrumento para fortalecer a própria categoria, favorecendo a compreensão dos "porque" e acrescentando argumentos para disputar o seu "lugar ao sol" de dentro de si própria enquanto profissão que tem uma memória e um corpo de conhecimento, do qual a sua história é um importante componente.

\footnotetext{
${ }^{1}$ Doutoranda da EEAN/UFRJ, Profa. Adj. IV-Depto Enf./ UFAL; membro do Nuphebras EEAN/UFRJ. UFRJ.

${ }^{2}$ Doutoranda da EEAN/UFRJ, Profa Adj.IV-Depto Enf./UFAL; membro do Nupegepen-EEAN/,

${ }^{3}$ Mestre em Enf.- EEUSP-SP; Profa Adj. III e Chefe do Depto Enf./UFAL.

${ }^{4}$ Dra em Enf. Prof Tit e Emérita do Depto Enf.Med.Cir.EEAP/UNIRIO; Pesq.Visitante EEAN" UFRJ; membro do Nuphebras e do Nupegepen/EEAN/UFRJ.
} 


\section{PORQUE A ENFERMAGEM É OBJETO DA HISTÓRIA}

Este trabalho é, ainda, parte dos estudos que estamos desenvolvendo para compreender a evolução histórica da enfermagem na sociedade ocidental, em particular da enfermagem brasileira, enquanto profissão de caráter eminentemente social e humanistico, estando portanto imbricada na evolução histórica da nossa civilização. Acatamos este pressuposto porque visualizamos a Enfermagem como uma prática social e historicamente construida, o que nos coloca em condições de tomá-la como um objeto de estudos históricos, compreendendo a história como conhecimento de mundo, olhando para a história não como vem sendo vista, mas na perspectiva proposta pela "História Nova", que trata muito mais de "entender, explicar, relacionar, contextualizar os acontecimentos sociais" (FRANCO; ZIBAS,1997, p.23) do que de fato apresentá-los seqüencialmente, como o fazia a história positivista.

A História Nova, surgida em Paris, com a revista "Annales", é a "história escrita como uma reação deliberada contra o paradigma tradicional..." Diferentemente deste paradigma, "a história nova se interessa por virtualmente toda a atividade humana, ou seja, tudo tem um passado que pode em principio ser reconstruido e relacionado ao restante do passado - história total" (BURKE, 1992, p.10). O que percebemos de importante é que a história nova, rompendo com a história tradicional, revela outros ângulos de visão dos acontecimentos, descobrindo novos objetos, dando vez e voz ao que antes era mudo! A base filosófica da história nova è o relativismo cultural.

Na perspectiva de novas formas de ver e fazer história, autores apresentam e explicitam "novos objetos, novos problemas e novas abordagens incluindo a arqueologia, a economia, a demografia, a religião, a literatura, a arte, a ciência e a política" (LE GOFF; NORA, 1995, p.130141). Ancoradas nesta abertura é que propomos a Enfermagem como um objeto da história.

A nova história pode e vem (pensamos) contribuindo muito para a escrita da história da enfermagem brasileira porque dá voz e visibilidade ao que não faz parte da história oficial: o mundo do trabalho, impondo à enfermeira funçöes administrativas e um volume excessivo de atividades, parece vir expropriando delas o desejo de ocupar-se com suas memórias, levandoas a dedicar-se (quando possivel) à busca de soluções dos problemas imediatos. Isso tende a mantê-las na posição que convém à instituição, um tanto alienada do que poderia significar uma fonte de poder que seria a consciência de sua identidade profissional, talvez até elevando sua confiança no seu próprio saber.

Pensamos que os estudos históricos que tenham a Enfermagem como objeto tangenciarão os problemas enfrentados pelas mulheres na luta pela sua emancipação. Entender esta questão nos ajudará a destacar a necessidade de nos vermos na condição feminina que está em processo de transformação, a duras penas e, dentro desta, analisarmos a nossa condição de mulheres enfermeiras, cuja luta também não é fácil, por visibilidade, respeito e autonomia.

A própria luta para despertar o interesse pela HEB é um exemplo do esforço desenvolvido no mundo sobre a história da Enfermagem e, no Brasil, desvendar a HEB implicará no (re)conhecimento da história do pais posto que uma e outra estão engendradas e uma (pais) condiciona a outra (Enfermagem) em seu jogo de relaçōes de poder dos grupos dominantes

A história nova, na produção do conhecimento da sociedade, deixa claro o que sempre foi obscuro, dando voz a quem nunca falou, permitindo ao vencido, ao marginalizado colocar a outra versão, a partir da "produção de novas fontes e da releitura dos documentos, como recomenda Certeau (2000, p.81). Pensamos ser válida esta nova tentativa de compreender a sociedade, uma vez que a história como foi contada, não serviu de exemplo para atenuar as desigualdades sociais ou evitar a repetição de tragédias como a perseguição racial, a distribuição desigual da riqueza e a desconsideração de principios filosóficos e éticos de valorização do ser humano.

Poderiamos até pensar em como seria importante, identificar as interfaces da história 
da enfermagem com a história das mulheres, história das doenças, história do corpo... Para Burke (1992, p. 23) o que essas abordagens têm de comum é a sua preocupaçăo com o mundo da experiência comum como seu ponto de partida. Acreditamos que muitas contribuições para o conhecimento da história da enfermagem poderiam advir desse tipo de estudo, tanto para a sociedade como para a própria categoria.

\section{DE QUAIS INSTRUMENTOS DA HISTÓRIA A ENFERMAGEM PODERÁ SE APROPRIAR}

Como estamos falando de novas abordagens, no bojo da história nova são apresentadas novas abordagens entre as quais se pode citar a História Oral, História da Leitura, onde säo estudados aspectos ligados à literatura e à formação dos hábitos de leitura nas diversas sociedades; a História da Vida Quotidiana, que se caracteriza por sua proposta de não reproduzir os mesmos padrōes da historiografia positivista, mas ressaltar a descontinuidade da história e estudar temas que nunca foram considerados história, como a cozinha, a mulher (MAROTTA, 1991, p.44); a Micro-história, a História Social, História das Imagens, que toma como objeto os monumentos, fotografias, filmes, as construções humanas e sua simbologia; História das Mentalidades, que trata de reconstruir a história através do estudo da mentalidade de uma determinada sociedade em determinado momento (MAROTTA, 1991, p.23),entre tantas outras. Temos percebido que a História Oral vem sendo muito procurada pelos alunos de pesquisa em $\mathrm{HEB}$, apresentando a vantagem de produzir fontes primárias - os documentos resultantes das entrevistas sobre objetos que ainda não haviam sido estudados. Vemos nesta abordagem a oportunidade de avançar muito na qualidade e quantidade do conhecimento sobre a enfermagem bem como na produção de fontes documentais, originadas da transcrição dos depoimentos dos sujeitos pesquisados.

Pelo que pudemos ler sobre a Micro-história, realmente é uma abordagem muito propicia para estudos da HEB porque é uma prática baseada na redução da escala de observação, em uma análise microscópica e em um estudo intensivo do material documental. Esse é o seu método: "a escala é tida como um objeto de análise que serve para medir as dimensões no campo dos relacionamentos ... que pode ser aplicado em qualquer lugar, independentemente das dimensões do objeto analisado" (BURKE, 1992, p.133)

Muitos pesquisadores e pretendentes a pesquisadores escolheram a História Social como abordagem de estudos sobre a HEB e ficamos refletindo sobre o uso de algumas novas abordagens, além das citadas anteriormente no texto, como a história das mulheres, história do corpo que nos parecem propicias para estudos da HEB porque tratam da prática da enfermagem essencialmente feminina e do corpo de quem ela cuida, além do seu próprio corpo...

Novos métodos foram incorporados para "dar conta" desses novos objetos, sendo os dados colhidos em fontes orais ou escritas. Essas fontes, na história nova, sofreram vasta ampliação, muito embora tenha sido problemática a sua utilização no começo por dificuldade de confiabilidade. As estratégias para coletar os dados são variadas e entre elas se pode lembrar as entrevistas abertas, gravadas, descrições, apropriação de partes do método quantitativo como a análise estatistica.

\section{PORQUE É IMPORTANTE A ENFERMAGEM RESGATAR SUA HISTÓRIA DESSA FORMA ENGAJADA E CONTEXTUALIZADA (COMO PARTE DE UM TODO)}

A História da Enfermagem Brasileira vem sendo (re)construida com esforço, pois, não são ainda suficientes os pesquisadores brasileiros que acreditam na importância de se preservar a memória da profissão, fato esse que pode ser visto como indicador para os escassos investimentos destinados a esses estudos pelos órgãos financiadores de pesquisa, em nosso 
pais.

Barreira (1999, p.88), refletindo sobre a "Memória e a História na construção de uma nova visão da enfermagem" fala sobre memória e poder. Define memória como um fenômeno individual fisiológico e afirma que a faculdade de memorizar é importante e fundamental, dentre outras coisas, para o desenvolvimento do processo ensino aprendizagem e para a integração da pessoa na sociedade. Seria interessante relacionar esta afirmativa com o fato de que "História da Enfermagem" é um conteúdo curricular que, a despeito de todas as reformas curriculares, permaneceu presente ao longo do tempo" (BARREIRA, 1999, p.).

Bosi (1994, p.47) diz que "a memória teria a função prática de limitar a indeterminação (do pensamento e da ação) e de levar o sujeito a reproduzir formas de comportamento que já deram certo"... "é essa reserva crescente a cada instante e que dispōe da totalidade da nossa experiência" (BOSI, 1994, p.48). Dai a importância de se preservar a memória das enfermeiras para construir a memória coletiva da enfermagem.

Em Bosi (1994, p.19) vemos como Marilena Chaui, destaca as estratégias pelas quais a memória individual pode ser manipulada pela ideologia dominante e ela deixa deduzir que acontece o mesmo com a memória coletiva, pois, a memória pode ser "confundida" pela "historia oficial celebrativa, história dos vencedores" uma vez que já foi demonstrado que "as lembranças pessoais e grupais são invadidas por outra 'história', por uma outra memória" ... que interpretamos tal como faz Barreira, (1999, p.88), como sendo a memória dos "estereótipos oficiais, necessários à sobrevivência da ideologia da classe dominante".

Neste sentido, acreditamos ser imperioso preservar a memória das enfermeiras, considerando-as como novos objetos de estudos que poderão ser dialéticamente discutidos à luz do pensamento de teóricos como Pierre Bourdieu, Agnes Heller, entre outros, que se ocupam do mundo social ou do cotidiano da vida.

Por todos esses argumentos, julgamos fundamental compreender que memória coletiva é conquista e é instrumento de poder como diz Barreira (1999, p.88) e porque é essencial que a enfermagem dê mais atenção à sua memória pois, sendo ela "vital para os grupos e as sociedades que lutam por reconhecimento, como é o caso da enfermagem", urge registrá-la, individual ou institucionalmente para que se possa visualizá-la em uma sintese futura, dando a essa construção a amplitude que tem em si mesma. É urgente também porque as enfermeiras, em alguns momentos, parecem precisar acreditar mais em seus conhecimentos, em sua capacidade de intervir com resolutividade nas situaçōes em que estão cuidando, para assegurarem reconhecimento e respeito por parte de sua clientela.

Sobre esta questão, é preciso considerar que a preservação da memória e a escrita da história estão intimamente ligadas ao trabalho de documentação, pois é ele que permite que os acontecimentos contemporâneos não se percam na velocidade do mundo atual e que seja possivel a realização de estudos históricos. A análise dessas fontes documentais, por sua vez, deve levar em conta a ideologia que está impregnada em cada uma dessas fontes. Elas devem ser submetidas ao confronto com as fontes não oficiais, com o que ainda não foi escrito para que os estudos assim produzidos retratem não só o pensamento dominante mas aquilo que de fato está(va) no consciente coletivo do grupo.

Não tem sido raro presenciar documentos, imagens serem descartadas sem que seus significados sejam identificados ou registrados. O prejuizo desta atitude talvez não possa ser visualizado imediatamente, mas o será no curso do próprio tempo, como hoje lamentamos por todo o conhecimento que não foi preservado de civilizações que existiram no passado. Nós mesmas sentimos em "nossa pele" a tristeza da destruição das fontes documentais, o que só aumenta a responsabilidade de encontrar o que ainda resta, tratá-las, conservá-las e produzir novas fontes que não permitam perder a memória coletiva da profissão.

Talvez esta nossa preocupação esteja ligada à percepção que temos da importância dos estudos sobre a HEB, como uma contribuição para superar as fragilidades (atuais) da nossa 
categoria, pois em nenhum lugar se percebe como o conhecimento pode ser libertador, como pode alavancar o desenvolvimento da consciência crítica. Quem sabe o conhecimento da história desta profissão nos permita compreender as razões que nos levaram ao afastamento do cuidado direto às pessoas, envolvendo-nos mais intensamente com o processo administrativo da unidade de trabalho: quiçá aponte pistas para a dificuldade que sentimos hoje em assumir a prática do cuidado cientifico de enfermagem, se não em todos os lugares mas pelo menos nas regiöes mais distantes dos grandes centros urbanos, como a região nordestina, por exemplo, lugar de onde viemos e onde trabalhamos, onde o trabalho feminino - como é o da grande maioria dos exercentes da enfermagem - ainda é pouco visivel, subordinado e pouco valorizado.

Acreditamos que muitos fatos que aprendemos no curso de graduação sobre a história da enfermagem brasileira ganhariam novos matizes se revistos à luz da memórias de tantas enfermeiras que presenciaram o jogo de interesses que determinaram a escolha do modelo em que foram formadas, as forças que sedimentaram seu padrão de comportamento, as lutas que empreenderam para organizarem-se enquanto categoria, as conseqüências que tiveram que arcar quando se recusaram a cumprir as ordens emanadas do poder vigente.

Pensamos que os argumentos apresentados são suficientes para justificar um convite a uma reflexão sobre o tema que abordamos, porém, julgamos importante acrescentar que, tomar a enfermagem como objeto de estudos históricos significa também trazer à tona seus conflitos, suas tradiçōes, suas origens verdadeiras e não aquelas plantadas pela ideologia dominante.

Por outro lado, as escolas tem sido provocadas a dar conta da demanda de estudos da HEB, sendo chamadas a assumir esta tarefa, principalmente em função de serem detentoras dos programas de pós-graduação, onde estão concentrados os pesquisadores de enfermagem. Em resposta, inicialmente foram trabalhos produzidos em caráter de resenha histórica, que não deixaram de ser o início da "massa de pesquisas" que possibilitará a síntese da HEB. Atualmente é significativo o número de estudos produzidos e nós mesmas nos sentimos parte deste esforço quando trazemos a proposta de estudar um recorte espacial distante dos grandes centros de pesquisa, que poderá trazer novas explicaçöes ou reforçar aquelas que já são conhecidas.

Além do mais, é muito enriquecedor para alunos, professores e profissionais, ter a possibilidade de "contar sua história a partir de seus próprios estudos, em vez de debruçar-se apenas sobre a história que outros escreveram, sem levar em conta contextos e circunstâncias locais, como se o particular não pudesse interferir no geral ou como se a trajetória da Enfermagem na Inglaterra de 1850 ou nos Estados Unidos de 1890 fosse igual ao Brasil de 1930. O exercicio da superação dessas dificuldades se dará pela valorização da mulher enfermeira. 0 conhecimento e confiança nesse conhecimento será fundamental; o estudo da história da profissão e de suas profissionais é parte intima deste processo.

Acrescentando a tudo que foi dito sobre as implicações do estudo da história da enfermagem para a construção da memória coletiva e formação da consciência critica da profissão, gostariamos apenas de citar Veyne (1995, p. 28) dizendo que "o esforço do trabalho histórico consiste em reencontrar a organização natural dos fatos" o que significaria entender e desvendar a trama que se encontra dentro, por trás dos fatos e que não está visivel.

Dentre todos os argumentos colocados nos estudos sobre a HEB a respeito do significado da história para a enfermagem, gostariamos de destacar a importância do trabalho que vem sendo feito de produção e tratamento de documentos, ainda incipiente em alguns lugares e, em outros, já estruturado como é o Centro de Documentação da Escola de Enfermagem Anna Nery, da Universidade Federal do Rio de Janeiro (EEAN/UFRJ).

Ao presenciar algumas discussőes sobre o estabelecimento das linhas de pesquisa da enfermagem, pudemos constatar a urgência do apelo pela criação dos núcleos de pesquisa, momento singular de integração entre profissionais da enfermagem e de outras categorias, entre o ensino de graduação e pós-graduação, entre a pesquisa nos seus diversos graus de abrangência e profundidade e em destaque a integração entre serviço e ensino, como se vê no 
Núcleo de História da Enfermagem Brasileira (Nuphebras), na EEAN/UFRJ, pois estudos históricos interessam a todos, indistintamente. É um momento onde se pode "ver" a movimentação da produção acadêmica e do trabalho, discutindo em condição de intercâmbio.

\title{
CONSIDERAÇÕES FINAIS: A NOSSA PROPOSTA
}

O que propomos é que, neste raciocinio, consideremos a enfermagem como novo objeto de uma história que ainda está em processo de construção. Vemos, aqui, a possibilidade de explorar o desenvolvimento da enfermagem engendrada em diferentes contextos sociais, em circunstâncias mais ou menos adversas, de modo que se possa empreender, no momento da grande sintese, a escrita de uma história na qual não esteja registrada apenas a visão dos vencedores, mas que contenha as diferentes vivências de muitas e diferentes enfermeiras.

Como conclusão vale refletir sobre o quanto de esforço deve ser investido nesta "missão" pois além de todas as questões colocadas, temos que lutar também com as dificuldades inerentes ao processo de trabalho da enfermagem e o que ele coloca como "parte" que cabe à enfermeira, sua condição de mulher na familia, e na sociedade, com a desvalorização do seu saber/fazer.

Acreditamos que nisto se encerra o poder libertador do conhecimento histórico.

\begin{abstract}
In this study we propose a reflection on nursing as an object of history. Our proposal is based on studies which have dealt with the history of nursing in Brazil and with the new perspectives of history studies. Our reflection is guided by an analysis of the history of nursing in Brazil and the social circumstances which determined the development of this profession in this context. This research adopted methodological proposals which are usually used in historical studies. The data collection was done through oral history and the analysis of documentary sources. The review of the social phenomenon, through the data collected, showed the importance of studies of historic nature and how much these can help on the understanding of the nursing professional identity as well as on the strengthening of this category. We hope that this project motivates the production of other works on this subject and calls the attention for the importance of preserving our historical memory.
\end{abstract}

KEYWORDS: History, Nursing, nursing history

RESUMEN:En este estudio proponemos reflexionar sobre la Enfermeria como objeto de la Historia. La propuesta está anclada en los estudios que se están realizando sobre la Historia de la Enfermeria Brasileña y en la apertura que la Historia Nueva confiere a los estudios históricos. Asi buscamos comprender la Historia de la Enfermeria Brasileña y las circunstancias sociales que han determinado el desarrolo de la profesión hacia una u otra dirección. Presentamos algunas propuestas metodológicas generalmente utilizadas en estudios históricos, que proponen la historia oral y el análisis de documentación como métodos de cómputo de datos. La relectura de los hechos sociales, a partir de los datos recogidos hace comprender la importancia de los estudios sobre la Historia de la Enfermeria y reconoce su identidad profesional, como una contribución para el fortalecimiento de la categoria. Pretendemos estimular la producción de nuevos trabajos sobre el tema y alertar hacia la necesidad de preservar nuestra memoria.

PALABRAS CLAVE: Historia, Enfermería, historia de la Enfermeria 
A enfermagem como objeto da história...

\section{REFERÊNCIAS BIBLIOGRÁFICAS}

BARREIRA, I. A. Memória e história para uma nova visão da enfermagem no Brasil. Rev. latino-am. enfermagem, Ribeirão Preto, v. 7, n. 3, p. 87-93, julho 1999.

BOSI, E. Memória e sociedade: lembranças de velhos. 3. ed. S. Paulo: Companhia das Letras, 1994

BURKE, P. A escrita da história: novas perspectivas. São Paulo: UNESP, 1992.

CERTEAU, M. DE. A escrita da história. Rio de Janeiro: Forense Universitária, 1982.

FRANCO, M.L. \& ZIBAS, D. Final do século: desafios da educação na América Latina. São Paulo: Cortez, 1997.

LE GOFF, J \& NORA, P. História: novos problemas, novas abordagens, novos objetos. Rio de Janeiro: F. Alves, 1995.

MAROTTA, C. O. A.. O que é história das mentalidades. Passos, São Paulo. Brasiliense, 1991. (Primeiros Passos)

VEYNE, P. M. Foucault revoluciona a história. In: VEYE, P. M. Como se escreve a história; 3. ed. Brasilia: Universidade de Brasilia, 1995. 